\title{
Editorial
}

\section{Transition into postsecondary education}

Dr. John Kregel has pulled together an outstanding issue on Postsecondary Education Programs, research, and other activities that are exemplary for people with disabilities. There has been over the years too little communication between postsecondary education programs such as community colleges and technical schools with vocational rehabilitation efforts. In this issue, there are several articles which specifically address the importance of involving the vast resources of postsecondary education institutions on behalf of people with disabilities. Dr. Kregel is joined by an illustrious group of contributors who provide cutting edge material in this area.

The whole area of transition from school into adulthood continues to require more attention throughout the world. Thousands of young people with disabilities are finishing their secondary school experiences and are now looking for real life work and their place in the community.

The entire concept of transition from school to adult should not be as difficult or complicated as we in the field of special education and rehabilitation have made it. Planning for transition and making this transition viable and exciting should be a welcome event for all involved and not a labor of simply moving paper from one agency to the next. Transition planning should not be complex; it does not parallel the complexity of finding a cure for AIDS or cancer, but instead, calls upon all who are directly involved to participate fully, be creative and respectful of the student and their family and to utilize all resources as fully as possible. Transition from school to adulthood is a human service problem and human service problems are usually best solved by creative people who look for a variety of strategies to achieve the end result. As we in the field, professionals and families alike, look toward the year 2000, we should ask what are the major activities and events that, if changed, would greatly benefit all young adults with disabilities? Below is a list of thoughts which are presented as consideration toward this goal.

1. All elementary and middle school programs for students with disabilities need to have an active vocational component. This means that career and vocational education must take a fairly prominent role in the child's daily educational program. It is not too early for the 11 year old with a behavior disorder, cerebral palsy or a learning disability to begin considering the different range of career options that might be available. While this is not to say that students that are 11 or 12 years old will go out and work on a job site, it does suggest that teachers must move away from their reliance on ditto sheets, workbooks, television, and blackboard work and instead focus on real life work experiences, opportunities, visits, and career oriented field trips. Most families are not accustomed to vocational experiences and intervention at the ages 
of 9-13 years old, but most research suggests that this level of intervention for children with special needs is extremely important (Wehman, 1992).

2. A functional curriculum approach to education is common sense, and needs to occur more often; this approach is one that business people, taxpayers, and parents in the community can understand. Edgar and Polloway (1994), Edgar (1987) and Wehman (1992) have all written eloquently calling for the field of special education to be much more functional in secondary curriculum approaches and design. Clark (1994) has recently echoed this plea as well as has Sternberg (1993). Yes, most parents want their children, regardless of disability, to be able to read, write and compute, but at the same time they expect that child to be able to function in the community with an increasing degree of competence as the child gets older. Functional curriculum involves making the skills that are presented interesting and useful. It is not difficult to teach from a workbook or run off ditto sheets; it is more challenging and difficult to individualize every student's program based on what they need at their different age level and skill level. It is much more difficult to design a program out of the classroom and off the school campus in the community, and in the home, and in work settings, but until this transformation is made in the 16000 plus local education agencies, we will never see economically disadvantaged or young adults with disabilities succeeding. The curriculum that they are receiving is too often grossly inappropriate for what their needs are. No amount of federal legislation will change this glaring error in the way special education services are delivered. Only teacher trainers, principals, school board representatives, central office administration, and above all, special education teachers will be able to begin to make these changes.

3. Instructional techniques and training strategies are paramount in and helping students become competent. There has been so much attention in the special education field over the past 20 years to where students are taught that the specific techniques that are effective have been dwarfed in the attention given to them.

4. The fourth area that requires substantial attention in transition planning is a dramatic upsurge in the amount and quality of employment and community living alternatives which are available to young adults. The continual perception that effective and meaningful transition can occur by only looking at the public school role is misguided; the receiving agencies and communities are absolutely critical in taking responsibility for and increasing the choices that are available. How can anyone realistically expect a young adult with a intellectual disability to consider transition very meaningful if the only option in town is a large sheltered workshop that houses 100-125 people with mental retardation? How can the young person with a severe behavior disorder that exits public school feel that they have meaningful community living choices when there are two supervised apartments that house six people total in a community of 150000 ? Yet these are, more often than not, the choices that face the young people with disabilities in America today. Adult service programs which span employment, residential, and community recreation must rise to the occasion of the thousands of students that have been entitled to special education. To fail to do so will negate the previous generation of special education efforts that have been made on behalf of millions of students with disabilities.

5. Public acceptance and employer understanding of the transition needs of young adults with disabilities is very important and a much greater outreach campaign is required by the disability community at large. Most members of the community are unaware of many of the challenges that students and their families face as they leave school to enter the chal- 
lenges of adulthood. Problems with gaining access to adult programs, transportation difficulties, and, in general, the difficulties associated with establishing a career are no different for people with disabilities than they are for other young people, but usually are significantly greater. There needs to be greater attention to involving the media and also key institutions within a community such as the church, community jaycees, and other recreational outlets such as the YMCA/YWCA.

In closing, this special issue of the Journal of Vocational Rehabilitation will directly address many of these key issues. There are many specific recommendations in these articles which will help create a better understanding of transition and the role of postsecondary education.

Paul Wehman

\section{References}

Clark, G. (1994) Functional curriculum. Teaching Exceptional Children.

Edgar, E. (1987) Secondary programs in special education: Are many of them justifiable? Except. Child. 53(6), 555-561.

Edgar, E. and Polloway, E. (1994) Education for adolescents with disabilities: Curriculum placement issues. J. Special Educ. 27 (4), 438-452.

Sternberg, L. (1993) Individuals with profound disabilities (3rd edn.) Austin, TX: PRO-ED.

Wehman, P. (1992) Life beyond the classroom. Baltimore: Paul Brookes Publishing Co. 